IP Periodica Polytechnica Civil Engineering

\author{
62(2), pp. 462-469, 2018 \\ https://doi.org/10.3311/PPci.11697 \\ Creative Commons Attribution (i)
}

RESEARCH ARTICLE

\section{Modeling of Creep Behavior of an Argillaceous Rock by Numerical Homogenization Method}

\author{
Hachimi Dahhaoui ${ }^{1}$, Naïma Belayachi2 ${ }^{2}$, Abdeldjalil Zadjaoui ${ }^{1}$
}

Received 09 November 2017; Revised 27 November 2017; Accepted 30 November 2017

\begin{abstract}
This paper is devoted to modeling the creep behavior of argillaceous rock and a comparison with experimental and numerical results from literature. The proposed time dependent modeling is based on a numerical homogenization method, matrix-inclusion material microstructure and a creep micromechanical model. The nonlinear viscosity of the argillaceous matrix is described by the creep model "Modified Time Hardening", while classical linear elasticity is applied for the calcite and quartz inclusions. The simulation accuracy was analyzed under single and multistage creep test. A satisfactory agreement between the simulation and the experimental results are obtained by assuming the main mineral phases of the Callovo-Oxfordian argillite. It was found that better agreements could be obtained when the multi-scale modeling is performed on sample with a given mineralogical composition and much more precisely volume fraction. The results show how numerical homogenization method is capable of effectively modelling macroscopic creep deformation.
\end{abstract}

\section{Keywords}

creep, numerical homogenization, micromechanics, claystone, experimental validation

\footnotetext{
1 Department of Civil Engineering, RisAM Laboratory,

University of Tlemcen, BP 230 Rue Abi Ayad Abdelkarim, 13000, Algeria

2 Université d'Orléans, Université de Tours, INSA Centre Val de Loire

Laboratoire de Mécanique Gabriel Lamé Polytech

Orléans, 8 rue Léonard de Vinci, 45072 Orléans, France

* Corresponding author, email: naima.belayachi@univ-orleans.fr
}

\section{Introduction}

The creep behavior of geomaterials (soils, rocks, concrete, etc.) is one of crucial interest to engineers and researchers. Beyond traditional projects and classical geotechnical problems (e.g., roads, dams, foundations...), the long-term behavior of these materials is widely studied for more ambitious advanced applications such as tunnel excavated through rocks [1], underground storage of radioactive waste [2], and geothermal energy [3].

In this very complex context, it is necessary to be able to predict long-term irreversible deformations in order to ensure the durability and safety of the various structures. Argilaceous rock known as Callovo-Oxfordian argillite is one of the geomaterials particularly studied in order to understand creep behaviour for the storage of radioactive waste because of its low permeability (around $10^{-20} \mathrm{~m}^{2}$ ) [4] and used for the storage of radioactive waste. This rock has been the subject of several investigations as: experimental studies by Zhang and Rothfuchs [5] who examined the influence of some factors on the long term behaviour (material anisotropy, scale effect, water content and sample origin). Fabre and Pellet [6] who analyzed the time dependent behavior of three rocks characterized by a high proportion of clay particles, and Gasc-Barbier et al. [7] who were conducted a testing program that focused on creep tests under triaxial and uniaxial compressive tests over different temperature conditions. Yang et al. [8] and Chen et al. [9] studied the creep behavior of other rocks. In addition, modelling of long term behaviour is most often based on macroscopic approaches through rheological models [10] [11] and constitutive models [12] [13] [14]. Time-dependent crack growth and rock damage during the viscous process were also modeled in [15] and [16]. Modeling investigations on the deferred behavior are generally based on the Perzyna's Theory [17]. This is the case of the elastoviscoplastic behavior model developed by Laigle and Kleine Model (hereafter L \& K). Based on this model, Plassart et al. [18] modeled creep for two successive stress stages based on triaxial tests. However, these models do not take into account the heterogeneous microstructure and mineralogical composition of the rock material, which have a significant effect on its mechanical properties [19]. Creep is 
caused by many and different complex mechanisms that are still not fully understood [20].

Ghasempour [21] emphasize the importance of the micromechanical modelling for considering rock more realistically. The micro-macro modelling has been widely used to integrate intrinsic properties of the material microstructure such as the porosity [22], the mineralogical composition [23] and microcrack growth [24]. Abou-Chakra Guéry et al. [25] proposed a modified incremental homogenization method in which the elasto-viscoplastic behavior of the argillaceous rock was of the Perzyna type with a Drucker Prager plasticity criterion. This model was then extended by the same authors [26] in order to predict the macroscopic behavior in relation to the mineralogical composition. Recently, other contributions have enriched the micromechanical modeling of time dependent behavior, such as: Huang et al. [27] with a new micromechanical model that takes into account porosity and mineral grains at two different scales. Also, Bikong et al. [28] who proposed a new model in which creep strain is induced by the time-dependent propagation of anisotropic microcracks inside the clay matrix. To the same end, Huang et al. [29] considered other specific properties of geomaterials such as the compressibility-dilatancy transition and influence of confining pressure.

In this paper, we propose to model the time dependent behavior of geomaterials on the basis of the macroscopic creep strain, using a numerical homogenization method. The approach adopted in this investigation is similar to [30], in which the authors attempted to consider the Argillite as a composite material (inclusion-matrix) using a finite element numerical approach. The essential difference between this investigation and previous works [26] [27] [29] [23] is that the local behavior of the clay matrix is described by a primary creep model for modeling the creep behavior as simply as possible. The modeling methodology, the micromechanical model and the parameter identification method were validated by using a wide range of experimental result published in the literature. The numerical homogenization method and the constitutive equations for the micromechanical model are presented in the following sections. The numerical macroscopic results are compared to those of other authors to show the accuracy of the simulation presented in this paper.

\section{Modeling procedure}

\subsection{Description of materials, geometrical and boundary conditions}

The material studied is taken from [25]. It is a sedimentary rock called Callovo-Oxfordian argillite which is a composite structure organized in the form of quartz grains, calcite and pores dispersed in a clay matrix [31] and [32].

The homogenization procedure consisted in identifying a periodic representative volume element (RVE) from the microstructural observations. The geometry of the RVE and the appropriate boundary conditions were guided by the study and simulations carried out by [30]. The RVE is a 3D representation of a periodic cubic cell, with spherical inclusions of quartz grains and calcite, reduced to $1 / 8$ because of the symmetry hypothesis Fig. 1.

The mineralogical composition changes significantly with depth in the rock layers, as shown in Fig. 2. The average proportions given in "Table 1" are calculated from the mineralogical compositions on total rock from three different depths.

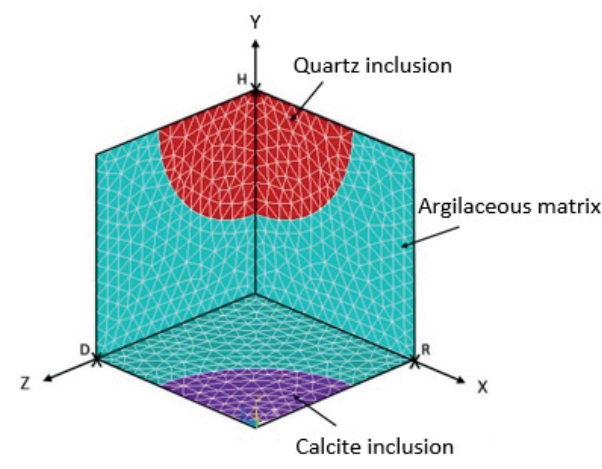

Boundary conditions

Fig. 1 Geometry and boundary conditions for RVE

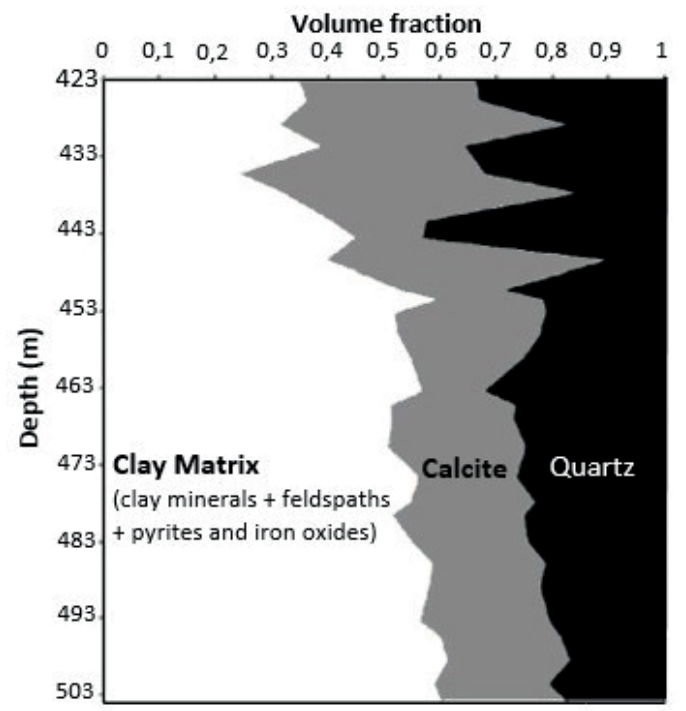

Fig. 2 Volume fraction variation of clay matrix, calcite and quartz grains as depth, drilling EST-205 [25]

Table 1 Mineralogical compositions [20] [33]

\begin{tabular}{lccc}
\hline Depth $(\mathrm{m})$ & Quartz $( \pm 10 \%)$ & Calcite $( \pm 5 \%)$ & Clay $( \pm 5 \%)$ \\
\hline 490 & 23 & 20 & 57 \\
503 & 25 & 27 & 48 \\
522 & 26 & 28 & 46 \\
Average & 25 & 25 & 50 \\
\hline
\end{tabular}

Modeling was conducted with the finite element code ANSYS. The mesh used consisted of SOLID187 tetrahedral elements (TET10, 10 nodes, 3 degrees of freedom at each node). It contains 10223 elements and 15488 nodes, making it possible not to burden the calculation while ensuring good precision in the results. This choice is validated by mesh sensitivity study of finite element type and mesh density on the results. The 
experimental solution was taken as reference and the error in the volume-averaged creep strain obtained in all other discretization with respect to the reference value is plotted in Fig. 3.

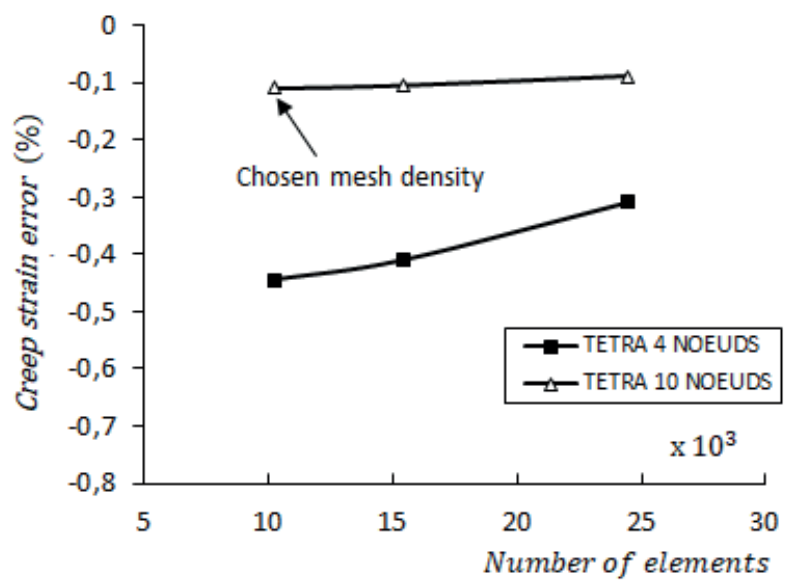

Fig. 3 Influence of element type and mesh size on numerical results.

\subsection{Constitutive behavior of components}

The mineral inclusions (quartz and calcite) have a linear elastic behavior while the clayey matrix is described by a nonlinear model. The choice of the best behavior model adapted for the clay matrix depends on the macroscopic response observed during the triaxial creep tests Fig. 4. In general, the standard response comprises three distinct phases:

- A first phase in which the creep strain increases relatively fast but then slows down; this step is called primary creep.

- The second stage is secondary creep, in which a constant evolution of the deformation in time occurs; it is relatively uniform and lasts longer.

- In the third phase, called tertiary creep, the deformation accelerates, leading eventually to fracture of the material [36] and [37].

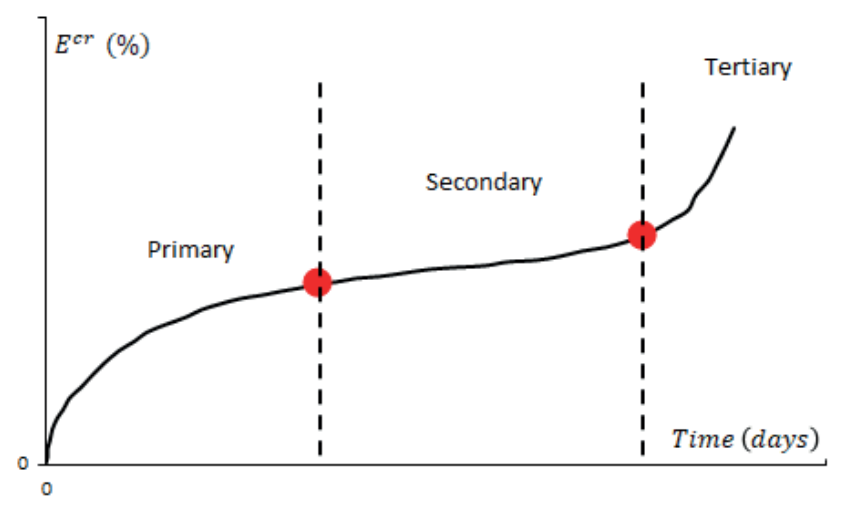

Fig. 4 Schematic different phases of time-dependent deformations for creep tests

The experimental curves used in this paper, taken from the studies [34] and [35] present only the first phase of creep. The behavior law chosen is that of Modified Time Hardening. It describes the primary creep associated with the viscosity of the clay matrix. This model is widely used for polycrystalline materials, and has shown its effectiveness in reproducing the experimental macroscopic response in several studies [36] [37] and [38]different modes of vessel failure may result in different regimes of melt release from the vessel, which determine initial conditions for melt coolant interaction and eventually coolability of the debris bed. The goal of this study is to define if retention of decay-heated melt inside the reactor pressure vessel is possible and investigate modes of the vessel wall failure otherwise. The mode of failure is contingent upon the ultimate mechanical strength of the vessel structures under given mechanical and thermal loads and applied cooling measures. The influence of pool depth and respective transient thermal loads on the reactor vessel failure mode is studied with coupled thermo-mechanical creep analysis. Efficacy of control rod guide tube (CRGT . As with most models relevant to metals and polymers, we used this model to describe the behavior of the clayey matrix. The material is considered to be isotropic. The abbreviation MTH for Modified time hardening will be used for the following equation:

$$
\varepsilon^{c r}=\frac{C 1}{C 3+1} \sigma^{C 2} t^{C 3+1} e^{-\frac{C 4}{T}}
$$

Where:

$\varepsilon^{\mathrm{cr}}:$ Creep strain

$\mathrm{C}_{\mathrm{i}}(\mathrm{i}=1.4)$ : Experimental material constants or parameters

$\sigma:$ Equivalent stress (Von Mises)

t: Time

e: Natural logarithm

T: Temperature

Since the creep test is performed over a narrow range of temperatures the dependency on this variable can be neglected i.e. the coefficient $C 4$ is considered zero. The time dependent creep equation is expressed as:

$$
\varepsilon^{c r}=\frac{C 1}{C 3+1} \sigma^{C 2} t^{C 3+1}
$$

The creep model described by "Eq. (2)" is dependent on loading applied and time. The number of parameters can increase if additional factors are considered [39]. This model remains limited to the description of the single-stage behavior for a given loading increments and load duration. However, the calculation of the deformations induced by multistage loading requires other variables to be considered. Since the first loading stage produces a modification of the microstructure, inelastic deformation is an appropriate indication of the microstructural state of the samples [40]. It is therefore considered as a variable containing the whole history of the material.

In Fig. 5, the MTH creep law performs well in the description of the behavior until the end of the first loading $(\sigma)_{1}$, when the initial state of the rock was well defined at point " $A$ ". However, the evolution of the deformations from the second loading 
stage becomes dependent on the inelastic deformation recorded at point " $C$ " [41]. The macroscopic response from the second loading increment $(\sigma)_{2}$ is determined by $E^{c r}$ corresponding to the instant $t_{C}$. This principle is retained in the present work, based on [42] [43] [41] in which the dependence on inelastic deformation seems effective for cases of multi loadings. This parameter is taken into account in the model during the homogenization step.

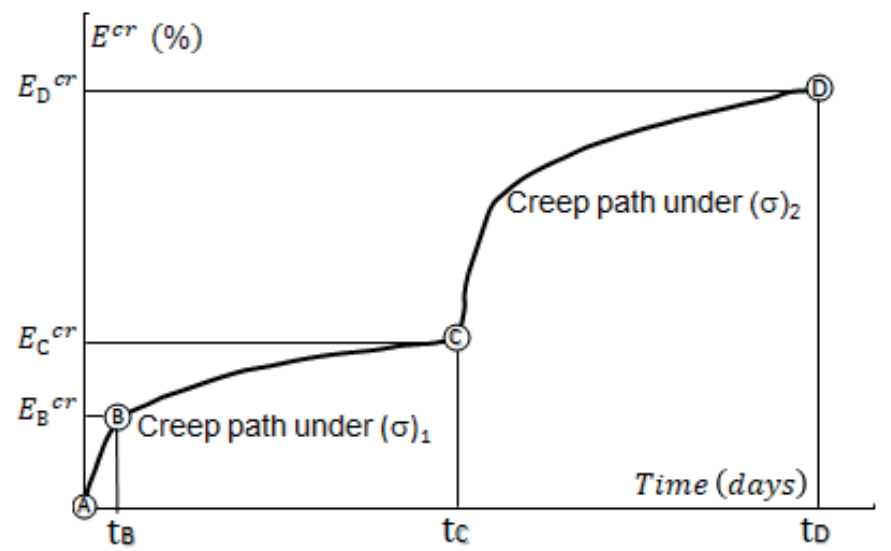

Fig. 5 Schematic evolution of the inelastic deformation for multiple-stage creep test

\subsection{Homogenization technique}

In this homogenization step, the macroscopic creep deformations $\left(E^{c r}\right)$ are computed as the average of the equivalent microscopic creep strain components $\left(\varepsilon^{c r}\right)$ :

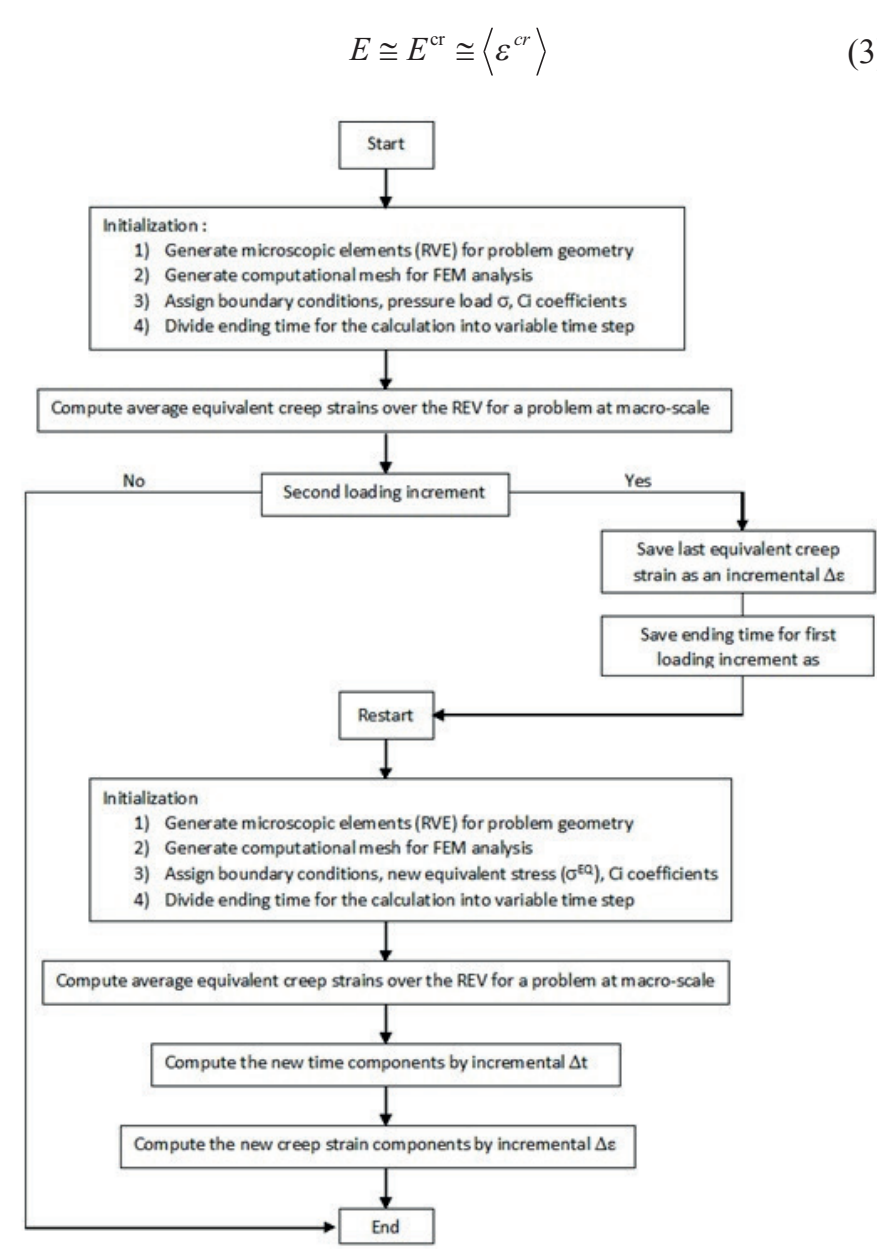

Fig. 6 Numerical modelling algorithm
Numerical algorithm described in Fig.6. is used for single-stage or multistage loading. To model single-stage loading tests, the macroscopic components are $\left(E_{n}^{c r}\right)$ at $\left(t_{n}\right)$ corresponding to the time interval $0 \leq t_{n} \leq t_{n}^{f}$. To model multistage loading tests, the final components $\left(E_{n}^{f}\right)$ at $\left(t_{n}^{f}\right)$ of the previous (creep) loading increment is used as the initial point for the following macroscopic components response: $\left(E_{n+1}^{c r}\right)$ at $\left(t_{n+1}\right)$, on the time interval $t_{n}^{f}<t_{n+1} \leq t_{n+1}^{f}$.

The numerical homogenization of the problem was carried out by determining the components of the macroscopic deformations computed as the volume average of microscopic components as follows:

$$
\left\langle\varepsilon^{c r}\right\rangle=\frac{1}{V} \int_{V} \varepsilon^{c r} d V
$$

\section{Result and discussion}

The numerical homogenization method used and its ability to reproduce the creep behavior of argillite in various compositions and loading conditions, was assessed. The parameters of the local behavior of the clay matrix were identified by an inverse analysis on the triaxial creep test EST 5698-5 [34], until the difference between the numerical result and experimental curve was minimal "Table 2".

Table 2 Material mechanical parameters

\begin{tabular}{|c|c|c|c|c|}
\hline \multicolumn{2}{|c|}{ Mechanical properties } & Argillaceous matrix & Calcite & Quartz \\
\hline \multirow{2}{*}{$\begin{array}{l}\text { Elastic } \\
\text { parameters }\end{array}$} & $\mathrm{E}(\mathrm{MPa})$ & 7000 & 84000 & 96400 \\
\hline & $\mathrm{n}(-)$ & 0,14 & 0,3 & 0,3 \\
\hline \multirow{3}{*}{$\begin{array}{l}\text { MTH model } \\
\text { parameters }\end{array}$} & C1 (-) & $1,7.10^{-6}$ & & \\
\hline & $\mathrm{C} 2(-)$ & 1,7 & & \\
\hline & C3 (-) & $-0,625$ & & \\
\hline
\end{tabular}

The elastic properties are taken from a study of Giraud et al. [44] The simulation results were then compared to the triaxial creep tests of the Callovo-Oxfordian argillite whose confining pressure was $12 \mathrm{MPa}$ [34].

Fig. 7 shows the validation of the numerical homogenization method taking into account the real mineralogical compositions as a function of their sampling depths and their loading condition. The RVE could be considered the mineralogical compositions as three phase composite satisfy the unity partition:

$$
f m+f c+f q u=1
$$

Where $f m, f c$ and $f q u$ stand for the volume fractions of clayey matrix, calcite and quartz inclusions, respectively.

It can be seen that there is usually a good agreement between experimental data and model predictions Fig. 7(a-d). The results indicate that the axial strain increases with the elapsed time, however accelerated creep leading to time-dependent failure process could not be taken into account, because only primary creep strains are considered. In addition, the changes of creep rate due to changes in mineralogical compositions are 


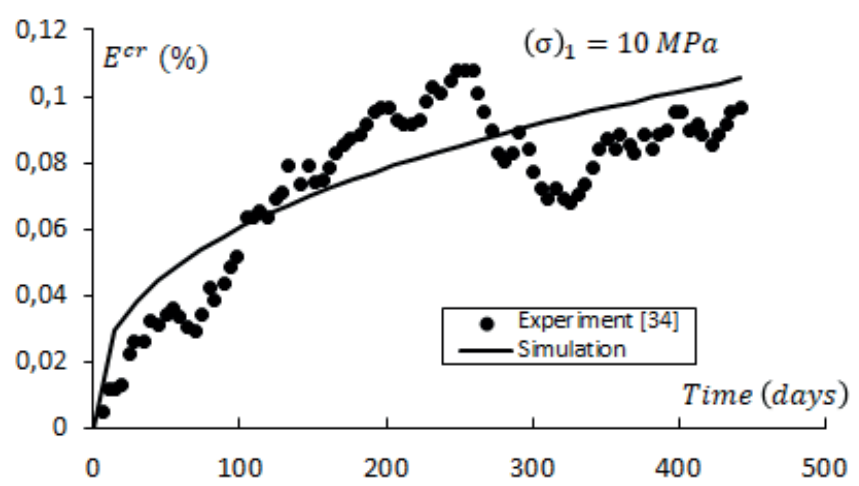

(a) Simulation of triaxial single-stage creep test of the Callovo-Oxfordian argillite : $\mathrm{fc}=21,7(\%)$, fqu $=21,3(\%)$

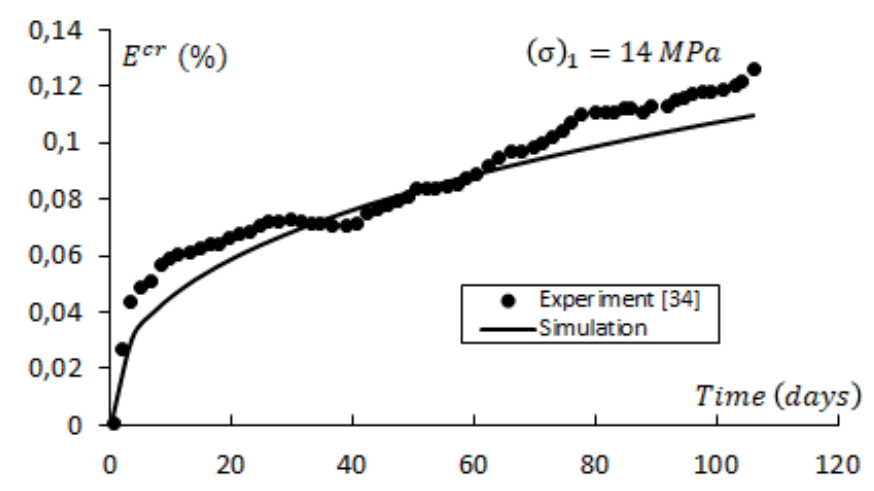

(b) Simulation of triaxial single-stage creep test of the Callovo-Oxfordian argillite : $\mathrm{fc}=21,7(\%)$, fqu $=21,3(\%)$

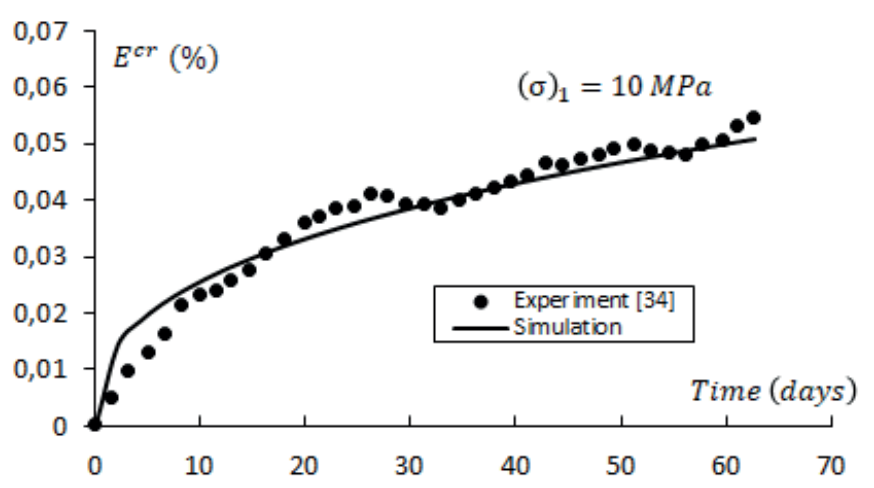

(c) Simulation of triaxial single-stage creep test of the Callovo-Oxfordian argillite: $\mathrm{fc}=21,9(\%)$, fqu $=21,2(\%)$

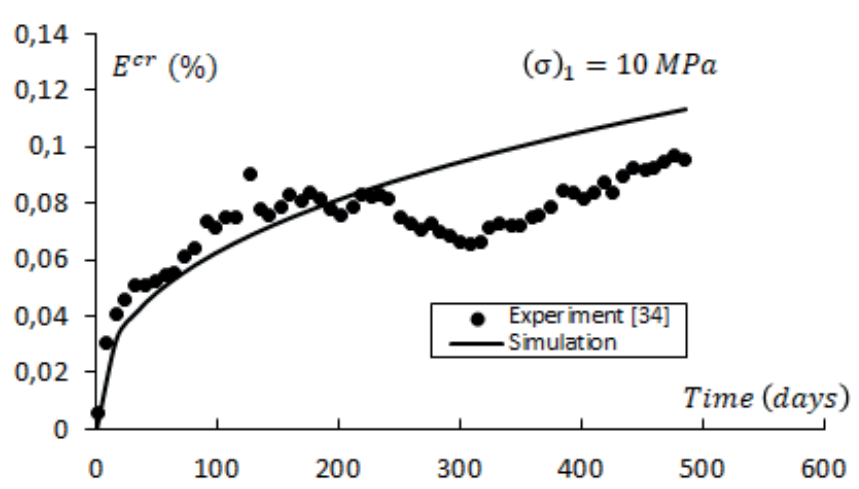

(d) Simulation of triaxial single-stage creep test of the Callovo-Oxfordian argillite : $\mathrm{fc}=21,6(\%)$, fqu $=17,4(\%)$

Fig. 7 Triaxial single-stage creep test. Comparison between experimentation and simulation presented (see Fig. 7(a) (c) and (d)). The main advantage of the model presented is the simulation of the creep behavior, based solely on the mineralogical composition variation without any calibration of the input parameters in the calculation algorithm. The influence of equivalent stress on creep strains rate are also clearly reproduced in Fig. 7(b).

In order to evaluate the differences between the response of numerical homogenization procedure used in this work and literature micromechanical models, a comparison is illustrated in Fig. 8.

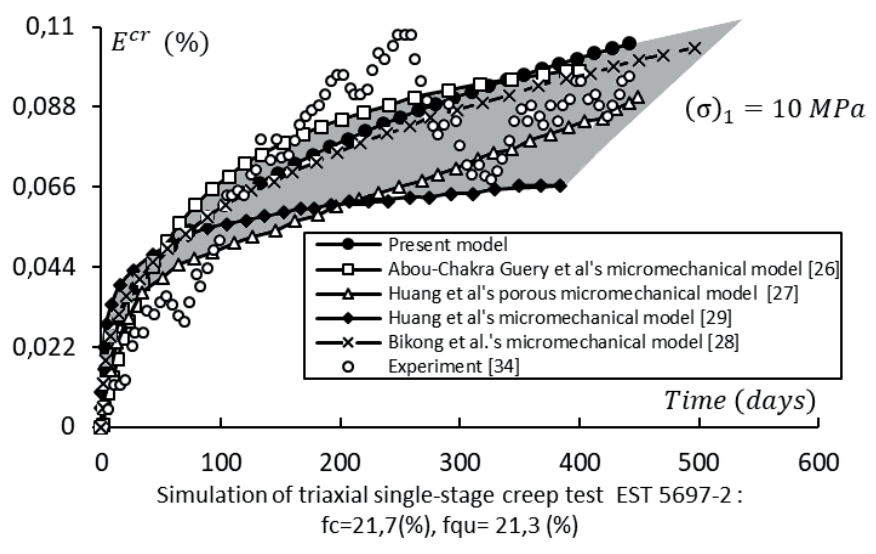

Fig. 8 Comparison between predictions of micromechanical models

The comparison shows a spindle within which the major part of the mechanical response of the $\mathrm{M} / \mathrm{H}-\mathrm{M}$ rock is located. The two models proposed by Huang et al. [27] and [29] form the lower boundary of the spindle, from $0 \leq t \leq 190$ days for [27] and $190 \leq t \leq 383$ days for [29]. They have two different shapes and produce fewer deformations than other models. The simulation results established by the models of Abou-Chakra Guéry et al [26], and Bikong et al. [28] agree on the result of the proposed model and together form the upper limit of the spindle.

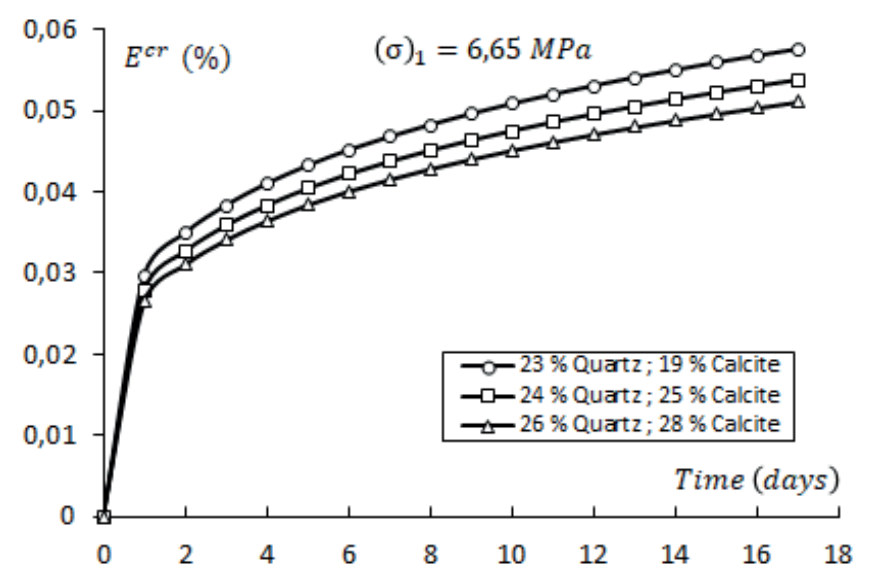

Fig. 9 Influence of inclusion's volume fraction on the creep behavior of the argillaceous rock

The sensitivity change of the inclusion volume was also analyzed by triaxial test simulations Fig. 9. The curves (deformations-time) obtained shows that the creep deformation decreases as the volume fraction of the inclusion increases. 
In the second part, the multistage triaxial creep tests was modeled, by the numerical algorithm as described in Fig. 6. The appropriate mineralogical composition of the RVE is not taken into account because the triaxial multistage creep test from [35] lack information on the depth of sampling. In this case, the average volumetric fraction of inclusions is used "Table 1" and the ability of the model to simulate rock behavior during multistage loading was evaluated in Fig. 10.

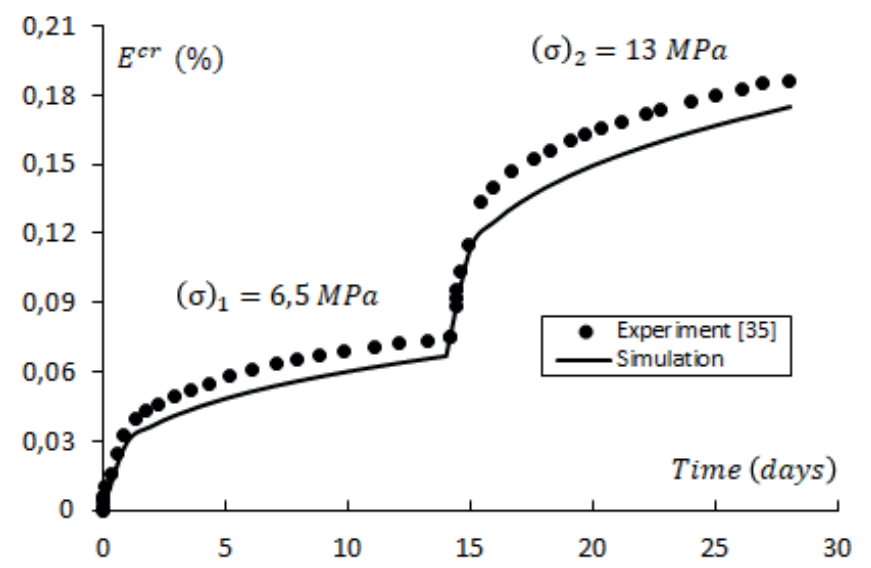

Fig. 10 Triaxial multistage creep test of the Callovo-Oxfordian argillite: comparison between experimentation and simulation

The comparison in Fig. 10 shows a satisfactory agreement of the results with differences that are smaller than 5\%. These differences can be justified by the fact that the input parameters of the model were based on the mineralogical composition, which varies with depth as given previously. In this case, satisfactory results could be obtained if the volumetric fraction of constituents were known. These results admit that all the mechanical parameters depend on the mineralogical composition [46]. However, more multistage creep tests need to be conducted to further investigate and improve the proposed numerical algorithm.

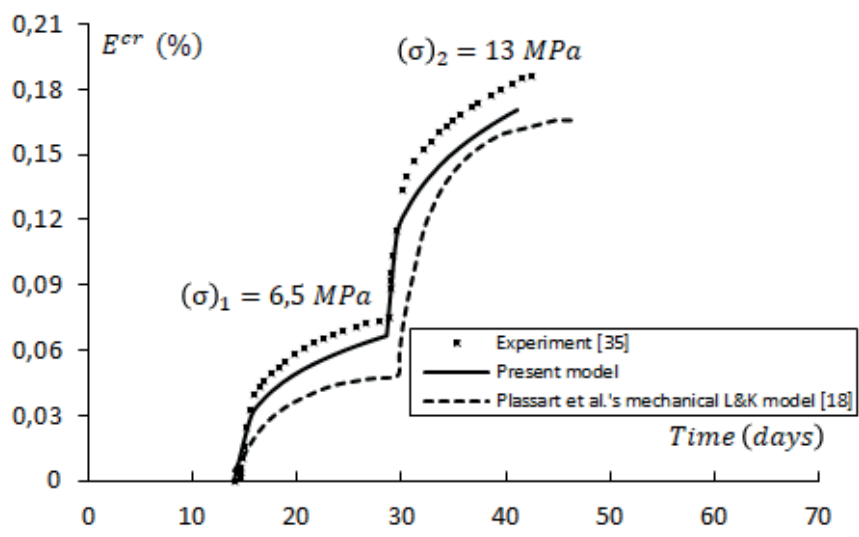

Fig. 11 Comparison with the L\&K macroscopic model

The comparison with the result established by the macroscopic model of L \& K [18] in Fig. 11, shows that the differences found by the proposed numerical homogenization method are less important than those observed in the case of macroscopic model L \& $\mathrm{K}$. This is mainly due to the coupling between the elastoplastic and viscoplastic mechanisms involved in the L \&

$\mathrm{K}$ [39], compared to the MTH model which is used mainly of the primary creep behavior (main behavior of this research).

\section{Conclusions}

The aim of this article was to propose a numerical modeling procedure using numerical homogenization and primary creep model to describe the clay matrix behavior for Argillite.

The numerical simulation provided by the proposed method have been compared with experimental data for both single stage and multistage creep test. In qualitative manner, the RVE configured according to the mineralogical composition gives macroscopic response adapted to the appropriate experimental curve. Some differences have been obtained in the case of triaxial multistage creep test. Probably this difference is due to the lack of precise information on the volume fraction and water content of sample. The numerical homogenization requires further characterization of mineralogical composition. It was clearly observed that the increase in the mineral grains proportions led to a decrease in creep strains. The paper makes comparison between simulated results and literature models. As expected, the proposed numerical homogenization method gives closer results to those of the micromechanical models, than those given by Plassart et al's mechanical L \& K model. It is concluded that the numerical homogenization and the analytical micromechanical models provide the most accurate prediction. The proposed procedure is able to model the creep behavior of the clay rock and can be extended to include other factors influencing the behavior of geomaterials as microcracks, imperfect interfaces, saturation state and temperature.

\section{Nomenclature}

\section{General terms}

E

E

$\mathrm{T}$

$\mathrm{t}$

$\mathrm{X}, \mathrm{Y}, \mathrm{Z}$

$\mathrm{Ci}_{(\mathrm{i}=1-4)}$

$\mathrm{V}$

\section{Greek symbols}

$\begin{array}{ll}\varepsilon & \text { Microscopic strain tensor } \\ v & \text { Poisson's ratio } \\ \sigma & \text { Equivalent stress } \\ \text { Superscripts and subscripts } \\ \mathrm{cr} & \text { Equivalent creep component } \\ \mathrm{f} & \text { Final component } \\ \mathrm{n} & \text { Time/strain step under (s)n } \\ \mathrm{n}+1 & \text { Time/strain step under (s)n+1 }\end{array}$

\section{Other symbols}

$<>$

( )

()$_{2}$
Young's modulus

Macroscopic strain

Temperature

Time

Element coordinate

Experimental material constants

Total volume of the unit cell

Microscopic strain tensor

Poisson's ratio

Equivalent stress

Equivalent creep component

Final component

Time/strain step under (s)n+1

Volume average of microscopic tensor

First stage creep loading

Second stage creep loading 
Abbreviations

RVE

MTH

L \& K

fc

fqu

Representative volume element

Modified Time Hardening

Laigle and Kleine Model

Volume fraction of calcite inclusion

Volume fraction of quartz inclusion

\section{References}

[1] Seifabad, M. C., Sadrnejad, S. A., Ebrahimi, D. "A study of swelling behaviour in a tunnel using finite element methods". Periodica Polytechnica Civil Engineering, 59(2), pp. 103-107. 2015. https://doi.org/10.3311/ PPci.7538

[2] Blanco Martín, L., Rutqvist, J., Birkholzer, J. T. "Long-term modeling of the thermal-hydraulic-mechanical response of a generic salt repository for heat-generating nuclear waste". Engineering Geology, 193, pp. 198-211. 2015. https://doi.org/10.1016/j.enggeo.2015.04.014

[3] Shao, S., Ranjith, P. G., Wasantha, P. L. P., Chen, B. K. "Experimental and numerical studies on the mechanical behaviour of Australian Strathbogie granite at high temperatures: An application to geothermal energy". Geothermics, 54, pp. 96-108. 2015. https://doi.org/10.1016/j.geothermics. 2014.11.005

[4] Belmokhtar, M., Delage, P., Ghabezloo, S., Conil, N. "Thermal Volume Changes and Creep in the Callovo-Oxfordian Claystone". Rock Mechanics and Rock Engineering, 50(9), pp. 2297-2309. 2017. https://doi. org/10.1007/s00603-017-1238-7

[5] Zhang, C., Rothfuchs, T. "Experimental study of the hydro-mechanical behaviour of the Callovo-Oxfordian argillite". Applied Clay Science, 26(14), pp. 325-336. 2004. https://doi.org/10.1016/j.clay.2003.12.025

[6] Fabre, G., Pellet, F. "Creep and time-dependent damage in argillaceous rocks". International Journal of Rock Mechanics and Mining Sciences, 43(6), pp. 950-960. 2006. https://doi.org/10.1016/j.ijrmms.2006.02.004

[7] Gasc-Barbier, M., Chanchole, S., Bérest, P. "Creep behavior of Bure clayey rock". Applied Clay Science, 26(1-4), pp. 449-458. 2004. https://doi. org/10.1016/j.clay.2003.12.030

[8] Yang, C., Daemen, J. J. K., Yin, J.-H. "Experimental investigation of creep behavior of salt rock". International Journal of Rock Mechanics and Mining Sciences, 36(2), pp. 233-242. 1999. https://doi.org/10.1016/S01489062(98)00187-9

[9] Chen, L., Wang, C. P., Liu, J. F., Liu, Y. M., Liu, J., Su, R., Wang, J. "A damage-mechanism-based creep model considering temperature effect in granite". Mechanics Research Communications, 56, pp. 76-82. 2014. https://doi.org/10.1016/j.mechrescom.2013.11.009

[10] Gálos, M. "Evaluation of the creep of rocks on the basic of a rheological material model". Periodica Polytechnica Civil Engineering, 32(3-4), pp. 247. 1988. https://pp.bme.hu/ci/article/view/3948

[11] Tomanovic, Z. "Influence of K 0 on the Creep Properties of Marl". Acta Geotechnica Slovenica, pp. 14-29. 2009.

[12] Shao, J. F., Zhu, Q. Z., Su, K. "Modeling of creep in rock materials in terms of material degradation". Computers and Geotechnics, 30(7), pp. 549-555. 2003. https://doi.org/10.1016/S0266-352X(03)00063-6

[13] Ma, G., Zhou, W., Ng, T. T., Cheng, Y. G., Chang, X. L. "Microscopic modeling of the creep behavior of rockfills with a delayed particle breakage model". Acta Geotechnica, 10(4), pp. 481-496. 2015. https://doi. org/10.1007/s11440-015-0367-y

[14] Gens, A., Manica, M., Vaunat, J., Ruiz, D. F. "Advances in Laboratory Testing and Modelling of Soils and Shales (ATMSS)". Advances in Laboratory Testing and Modelling of Soils and Shales. Springer, Cham, pp. 37-44. 2017. https://doi.org/10.1007/978-3-319-52773-4
[15] Li, X., Shao, Z. "Micro-macro modeling of brittle creep and progressive failure subjected to compressive loading in rock". Environmental Earth Sciences, 75, pp. 583. 2016. https://doi.org/10.1007/s12665-016-5365-3

[16] Wang, Q. Y., Zhu, W. C., Xu, T., Niu, L. L., Wei, J. "Numerical Simulation of Rock Creep Behavior with a Damage-Based Constitutive Law". International Journal of Geomechanics, 17(1), pp. 04016044. 2016. https:/doi. org/10.1061/(ASCE)GM.1943-5622.0000707

[17] Perzyna, P. "Fundamental problems in viscoplasticity. Advances in applied mechanics". Advances in Applied Mechanics, 9, pp. 243-377. 1966. https://doi.org/10.1016/S0065-2156(08)70009-7

[18] Plassart, R., Fernandes, R., Giraud, A., Hoxha, D., Laigle, F. "Hydromechanical modelling of an excavation in an underground research laboratory with an elastoviscoplastic behaviour law and regularization by second gradient of dilation". International Journal of Rock Mechanics and Mining Sciences, 58, pp. 23-33. 2013. https://doi.org/10.1016/j. ijrmms.2012.08.011

[19] Nakov, D., Markovski, G., Arangjelovski, T., Mark, P. "Experimental and Analytical Analysis of Creep of Steel Fibre Reinforced Concrete". Periodica Polytechnica Civil Engineering, 62(1), pp. 226-231. 2018. https:// doi.org/10.3311/PPci.11184

[20] Hu, D. W., Zhang, F., Shao, J. F., Gatmiri, B. "Influences of mineralogy and water content on the mechanical properties of argillite". Rock Mechanics and Rock Engineering, 47(1), pp. 157-166. 2014. https://doi. org/10.1007/s00603-013-0413-8

[21] Ghasempour, N., Moosavi, M., Aghighi, M. A. "A micromechanical model to estimate borehole collapse pressure". Periodica Polytechnica Civil Engineering, 61(3), pp. 581-589. 2017. https://doi.org/10.3311/PPci.9979

[22] Shen, W. Q., Shao, J. F., Kondo, D., Gatmiri, B. "A micro-macro model for clayey rocks with a plastic compressible porous matrix". International Journal of Plasticity, 36, pp. 64-85. 2012. https://doi.org/10.1016/j.ijplas. 2012.03.006

[23] Abou-Chakra Guéry, A., Cormery, F., Shao, J. F., Kondo, D. "A comparative micromechanical analysis of the effective properties of a geomaterial: Effect of mineralogical compositions". Computers and Geotechnics, 37(5), pp. 585-593. 2010. https://doi.org/10.1016/j.compgeo.2010.02.008

[24] Lu, Y., Elsworth, D., Wang, L. "A dual-scale approach to model timedependent deformation, creep and fracturing of brittle rocks". Computers and Geotechnics, 60, pp. 61-76. 2014. https://doi.org/10.1016/j.compgeo. 2014.04.001

[25] Abou-Chakra Guéry, A., A.Cormery, F., Shao, J. F., Kondo, D. "A micromechanical model for the elasto-viscoplastic and damage behavior of a cohesive geomaterial". Physics and Chemistry of the Earth, Parts A/B/C, 33(S1), pp. S416-S421. 2008. https://doi.org/10.1016/j.pce.2008.10.007

[26] Abou-Chakra Guéry, A., Cormery, F., Shao, J. F., Kondo, D. "A multiscale modeling of damage and time-dependent behavior of cohesive rocks". International Journal for Numerical and Analytical Methods in Geomechanics, 33(5), pp. 567-585. 2009. https://doi.org/10.1002/nag.727

[27] Huang, Y., Shen, W. Q., Shao, J. F., Abou-Chakra Guéry, A., Jia, Y. "Multiscale modeling of time-dependent behavior of claystones with a viscoplastic compressible porous matrix". Mechanics of Materials, 79, pp. 25-34. 2014. https://doi.org/10.1016/j.mechmat.2014.08.003

[28] Bikong, C., Hoxha, D., Shao, J. F. "A micro-macro model for time-dependent behavior of clayey rocks due to anisotropic propagation of microcracks". International Journal of Plasticity, 69, pp. 73-88. 2015. https:// doi.org/10.1016/j.ijplas.2015.02.001

[29] Huang, Y., Abou-Chakra Guéry, A., Shao, J. F. "Incremental variational approach for time dependent deformation in clayey rock". International Journal of Plasticity, 64, pp. 88-103. 2015. https://doi.org/10.1016/j. ijplas.2014.07.003 
[30] Belayachi, N., Do, D. P., Hoxha, D. "A note on the numerical homogenisation of the mechanical behaviour of an argillaceous rock". Computers and Geotechnics, 41, pp. 70-78. 2012. https://doi.org/10.1016/j.compgeo. 2011.11.007

[31] Yven, B., Sammartino, S. "Mineralogy, texture and porosity of CallovoOxfordian argillites of the Meuse/Haute-Marne region (eastern Paris Basin)". Mémoires de la société géologique de France, 178, pp. 73-90. 2007.

[32] Chiarelli, A. S., Shao, J. F., Hoteit, N. "Modeling of elastoplastic damage behavior of a claystone". International Journal of Plasticity, 19(1), pp. 23-45. 2003. https://doi.org/10.1016/S0749-6419(01)00017-1

[33] Zhang, F. "Comportement mécanique des argilites de MHM - influences de la saturation, de la composition minéralogique et de la température". pp. 1-141. 2012. https://ori-nuxeo.univ-lille1.fr/nuxeo/site/esupversions/ d67a2c2d-a1ed-4a8f-b2a6-3e93d1936d68

[34] Do, D. P. "Application des approches d'homogénéisation à l'étude des propriétés thermo-hydro-mécaniques des roches. Application aux argilites". Vandoeuvre-les-Nancy, INPL. 2008.

[35] Plassart, R. "Modélisation hydromécanique du comportement des ouvrages souterrains avec un modèle élastoviscoplastique". Doctoral dissertation, Vandoeuvre-les-Nancy, INPL. 2011.

[36] Brot, C. C., Etsion, I., Kligerman, Y. "A contact model for a creeping sphere and a rigid flat". Wear, 265(5-6), pp. 598-605. 2008. https://doi. org/10.1016/j.wear.2007.12.003

[37] Soare, S., Bull, S. J., Neil, A. G. O., Wright, N., Horsfall, A., Santos, J. M. M. "Nanoindentation assessment of aluminium metallisation ; the effect of creep and pile-up". Surface and Coatings Technology, 178(3), pp. 497-503. 2004. https://doi.org/10.1016/S0257-8972(03)00918-6

[38] Villanueva, W., Tran, C. T., Kudinov, P. "Coupled thermo-mechanical creep analysis for boiling water reactor pressure vessel lower head". Nuclear Engineering and Design, 249(June 2016), pp. 146-153. 2012. https://doi.org/10.1016/j.nucengdes.2011.07.048
[39] Desai, C. S. "Constitutive Modeling and Computer Methods in Geotechnical Engineering". Acta Geotechnica Slovenica, 7(1), pp. 5-29. 2010.

[40] Brantut, N., Heap, M. J., Baud, P., Meredith, P. G. "Rate- and strain-dependent brittle deformation of rocks". Journal of Geophysical Research: Solid Earth, 119(3), pp. 1-19. 2014. https://doi.org/10.1002/2013JB010448

[41] Yin, J., Graham, J. "Equivalent times and one-dimensional elastic viscoplastid modelling of time-dependent stress-strain behaviour of clays". $\mathrm{Ca}$ nadian Geotechnical Journal, 31(1), pp. 42-52. 1994.

[42] Wang, Z., Asce, A. M., Wong, R. C. K., Asce, M. "Strain-Dependent and Stress-Dependent Creep Model for a Till Subject to Triaxial Compression". International Journal of Geomechanics, 16(3), pp. 1-12. 2015. https://doi.org/10.1061/(ASCE)GM.1943-5622.0000583

[43] Wang, Z., Wong, R. C. K. "Strain-Dependent Creep Behavior of Athabasca Oil Sand in Triaxial Compression". International Journal of Geomechanics, 17(1), p. 04016027. 2016. https://doi.org/10.1061/(ASCE)GM.19435622.0000670

[44] Giraud, A., Huynh, Q. V., Hoxha, D., Kondo, D. "Effective poroelastic properties of transversely isotropic rock-like composites with arbitrarily oriented ellipsoidal inclusions". Mechanics of Materials, 39(11), pp. 1006-1024. 2007. https://doi.org/10.1016/j.mechmat.2007.05.005

[45] Farhat, F., Shen, W. Q., Shao, J. F. "A micro-mechanics based viscoplastic model for clayey rocks". Computers and Geotechnics, 89, pp. 92-102. 2017. https://doi.org/10.1016/j.compgeo.2017.04.014

[46] Armand, G., Conil, N., Talandier, J., Seyedi, D. M. "Fundamental aspects of the hydromechanical behaviour of Callovo-Oxfordian claystone: From experimental studies to model calibration and validation". Computers and Geotechnics, 85, pp. 277-286. 2017. https://doi.org/10.1016/j.compgeo. 2016.06 .003 